\title{
CROSS SECTIONAL STUDY REGARDING KNOWLEDGE, ATTITUDE AND AWARENESS AMONG ADOLESCENTS ON HEALTH, NUTRITION AND PSYCHOSOCIAL ASPECTS
}

Suguna. $\mathrm{S}^{1}$, Hemachandra Reddy ${ }^{2}$

\section{HOW TO CITE THIS ARTICLE:}

Suguna. S, Hemachandra Reddy. "Cross sectional study regarding knowledge, attitude and awareness among adolescent on health, nutrition and psychosocial aspects". Journal of Evolution of Medical and Dental Sciences 2013; Vol2, Issue 29, July 22; Page: 5458-5465.

ABSTRACT: OBJECTIVE:To determine the awareness among medical and paramedical adolescent students regarding various aspects like nutrition, health and psychosocial, and to educate them on those issues. MATERIALS AND METHODS: This is a cross sectional descriptive study. We used pre-tested, structured, self-administered questionnaire regarding various aspects of adolescence like nutrition, health, education, development, and psychosocial factors. The questionnaire was developed after review of literature and pilot tested.

Study subjects included 400 adolescent college going students between the age group of 16-19 years, studying in medical, pharmacology and nursing colleges. RESULTS: Of the 400 adolescent students, $47.3 \%$ were aware of daily nutritional needs, $43.8 \%$ were aware of usage of fats and oils, $49 \%$ were aware about the health care during pregnancy, $35.5 \%$ of them use helmet and $20.5 \%$ of them had suicidal tendencies. CONCLUSION: The knowledge regarding nutrition and development were good where as in some like health and psycho social aspects, the knowledge and attitude were similar to nonmedical / paramedical students of same age group in various other similar studies and thus there is a need for special adolescent education in medical and paramedical students.

KEY WORDS: adolescence, health, nutrition.

INTRODUCTION: Adolescents are young people between the ages of 10 and 19 years. According to WHO, nearly $2 / 3^{\text {rd }}$ of premature deaths and $1 / 3^{\text {rd }}$ of total disease burden in adults are associated with conditions or behavior that began in their youth, including: tobacco use, a lack of physical activity, unprotected sex or exposure to violence. Adolescence is a period of rapid development with changes in body shape and size. In addition to physical changes that occur, there is progress in maturation of cognitive, Psychological and social abilities.

Adequate nutrition, healthy eating habits and physical exercise at this age are foundations for good health in adulthood. At the peak of the adolescent growth spurt, the nutritional requirements may be twice as high as those of the remaining period of adolescence. Fast food restaurants have changed the way adolescents eat and contribute significantly to health problems .Soft drinks are a major source of added sweeteners in the diets of adolescents ${ }^{1}$, and increasing intake of caffeinated drinks, with increasing media advertisements ${ }^{2}$. If these eating habits become established, they could place young people at a higher risk for certain chronic illnesses, especially for cardiovascular diseases and certain forms of cancers ${ }^{3}$.The BMI limitations are useful in clinical and population health to identify over fat adolescents and those who have greater risk of developing weight-related cardiovascular diseases ${ }^{4}$.

Self-consciousness increases exponentially in response to the somatic transformations of puberty. Girls, in particular, are at risk for viewing themselves as overweight. Severe body image distortions, such as anorexia nervosa, also tend to appear at this age. Bulimia which is 
more common than anorexia can occur in up to $5 \%$ of adolescent females. The condition may be then perpetuated by the biochemical changes induced by weight loss, ketosis, and the impact of the ensuing malnutrition on the brain (starvation illness) ${ }^{5}$. Healthy diet can prevent health problem such as obesity, dental caries and iron deficiency anemia and lowers the risk of three leading causes of death; cancer, heart disease and stroke.

Adolescents are self conscious about their appearance. Acne can cause lowered self esteem and social withdrawal. Unfortunately relatively few adolescents see clinician for treatment; instead using over - the- counter preparations that are aggressively marketed to a vulnerable audience ${ }^{6}$.

Sexuality includes not only sexual behaviors but also interest and fantasies, sexual orientation, attitudes toward sex and its relationship to emotions, and awareness of socially defined roles and mores. Reliable information about sexuality in general and contraception in particular, remains sparse. Ready access to pornography on the Internet may increase the risk of premature sexual activity or exploitation. Up to $60 \%$ of all new HIV infections occur among 15 to 24 year olds. According to WHO every day 2400 more young people get infected with HIV and globally there are more than 5 million young people living with HIV /AIDS. Currently only $36 \%$ of young men and $24 \%$ of young women have comprehensive and correct knowledge that they need to protect themselves ${ }^{7}$.

Some of the health issues affecting young people are early pregnancy and childbirth. About 16 million girls aged 15 to 19 years give birth every year, roughly $11 \%$ of all births worldwide. Vast majority in developing countries. Conditions associated with pregnancy under the age of 15 years are preterm birth, still births, low birth weight (4 times higher), sudden infant death syndrome (SIDS) (3 times higher), congenital malformations (1.5 times) more than other ages. Pregnant adolescents are more likely to have unsafe abortions. Pregnant teens have long term socio economic disadvantages including lack of advancement in education, poverty and poor out comes in emotional and social development of their children'.

Alcohol use starts at a young age. worldwide $14 \%$ of adolescent girls and $18 \%$ of boys in low and middle income countries are reported to use alcohol .It reduces self control and increases risk behavior. Worldwide, $5 \%$ of all deaths of young people between the ages of 15 and 29 year are attributable to alcohol use ${ }^{9}, 10$.Vast majority of tobacco users worldwide began when they are adolescents. Today an estimated 150 million young people use tobacco.

Rubella and congenital rubella syndrome were documented as significant public health problems. A comprehensive approach is necessary, including introducing rubella vaccine in the routine program, assuring immunity among women of child bearing age, strengthening routine immunization, integrating rubella surveillance with measles ${ }^{4}$.

India, with approximately one sixth of the world's population, bears one fifth of the world's burden of cervical cancer11. Vaccines preventing human papillomavirus (HPV) infection, the primary cause of cervical cancer ${ }^{12}$, offer dramatic new opportunities for reducing cervical cancer related deaths. Increase in incidence rates for some HPV-associated cancers and low vaccination coverage among adolescents underscore the need for additional prevention efforts for HPV-associated cancers, including efforts to increase vaccination coverage ${ }^{13}$.

Unintentional injuries are leading causes of death and disability among young people. Road traffic injuries take the lives of staggering 1049 young people every year.

Injuries are major threat to adolescent health. Apart from being a leading cause of death among young people, injuries are also recognized as major contributory factors to morbidity, disability and other costs such as lost future work and quality of life. According to WHO in European countries, head injuries contribute to around $75 \%$ of deaths among motorized two- 
wheeler users; in some low-income and middle-income countries head injuries are estimated to account for up to $88 \%$ of such fatalities.

MATERIALS AND METHODS:This is a cross sectional descriptive study conducted in B.G.Nagara, mandya district, Karnataka, India. We used pre-tested, structured, self-administered questionnaire among study subjects containing their socio demographic profile and the questions regarding various aspects of adolescence like nutrition, health, education, development, and psychosocial factors. The questionnaire was developed after review of literature and pilot tested.

Study subjects included adolescent college going students between the age group of 1619years, studying in medical, pharmacology and nursing colleges. Data was checked for missing values, entered and analyzed using SPSS version 16.

Statistical data contains percentages and proportions.

\section{RESULTS:}

Table 1. Distribution of study subjects with respect to awareness regarding nutrition among study subjects

\begin{tabular}{|l|l|l|l|}
\hline SL.NO & NUTRITION & AWARENESS & $\%$ \\
\hline 1 & Exclusive breast feeding & 371 & 92.8 \\
\hline 2 & Junk foods and obesity & 376 & 94 \\
\hline 3 & Vitamin D source & 319 & 79.8 \\
\hline 4 & Vitamin A deficiency & 231 & 57.8 \\
\hline 5 & Quality proteins & 271 & 67.8 \\
\hline 6 & Oil and fat & 175 & 43.8 \\
\hline 7 & Daily nutrition & 189 & 47.3 \\
\hline
\end{tabular}

$47.3 \%$ are aware of daily nutritional needs, $43.8 \%$ are aware of usage of fats and oils, $49 \%$ are aware about the health care during pregnancy, and nutritional needs. The knowledge about daily vitamin requirements and its availability is not uniform among students, awareness among nursing students is less, compared with medical students requires education (data not shown).

Table2. Distribution of study subjects with respect to awareness regarding health among study subjects

\begin{tabular}{|l|l|l|l|}
\hline SL NO & HEALTH & AWARENESS & $\%$ \\
\hline 1 & Early pregnancy/age of marriage & 368 & 92 \\
\hline 2 & Acne and oily diet & 175 & 43.8 \\
\hline 3 & Delivery by trained personnel & 339 & 84.8 \\
\hline 4 & Sports and games & 278 & 69.5 \\
\hline 5 & Alcohol and smoking hazards & 360 & 90 \\
\hline
\end{tabular}

Risk of pregnancy before 18yrs was known among large majority of pupils (92\%), and knowledge of all deliveries that should be conducted by trained personnel was $84.8 \%$. Around $90 \%$ had told that occasional consumption of smoking and alcohol is acceptable. 
Table3. Distribution of study subjects with respect to awareness regarding psychosocial issues among study subjects

\begin{tabular}{|l|l|l|l|}
\hline SL NO & PSYCHOSOCIAL & AWARENESS & $\%$ \\
\hline 1 & Use of helmet & 142 & 35.5 \\
\hline 2 & Need for sex education & 359 & 89.8 \\
\hline 3 & Age of voting & 351 & 87.8 \\
\hline 4 & Female infanticide & 346 & 86.5 \\
\hline 5 & Population control & 208 & 52 \\
\hline 6 & Suicidal tendencies & 82 & 20.5 \\
\hline 7 & $\begin{array}{l}\text { HIV transmission and usage } \\
\text { of condoms to prevent } \\
\text { transmission }\end{array}$ & 253 & 88.3 \\
\hline
\end{tabular}

Knowledge regarding need for usage of condoms to prevent transmission of HIV and other STD'S, female infanticide and population control was $88.3 \%$ and uniform in all sectors of studying subjects

Table4. Distribution of study subjects with respect to awareness regarding growth and development among study subjects

\begin{tabular}{|l|l|l|l|}
\hline SL NO & GROWTH AND DEVELOPMENT & AWARENESS & $\%$ \\
\hline 1 & Growth in adolescents & 287 & 71.8 \\
\hline 2 & Intra uterine growth & 196 & 49 \\
\hline
\end{tabular}

Regarding growth and development, the growth spurt during adolescence is known in $71.8 \%$ subjects. The effect of pregnant women working habits on fetal growth was known only among $49 \%$.

Table5. Distribution of study subjects with respect to awareness regarding education among study subjects

\begin{tabular}{|l|l|l|l|}
\hline SL NO & EDUCATION & AWARENESS & $\%$ \\
\hline 1 & Acquiring knowledge & 227 & 56.3 \\
\hline 2 & Internet usage & 178 & 44.5 \\
\hline 3 & Extracurricular involvement & 278 & 69.5 \\
\hline
\end{tabular}

Only $35.5 \%$ of students admitted that they wear helmet while riding two wheelers and Suicidal ideation were noted among $20.5 \%$

Figure 1. A pie diagram showing adolescents taking beverages 


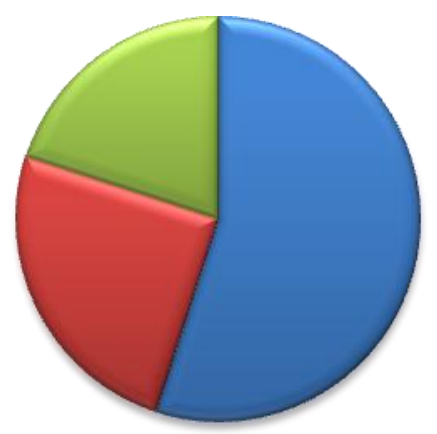

D Coffee/tea $55 \%$

- Pepsi/Cola $25 \%$

Milk $20 \%$

Figure 2. A pie diagram showing in adolescent subjects with whom they share their feelings better

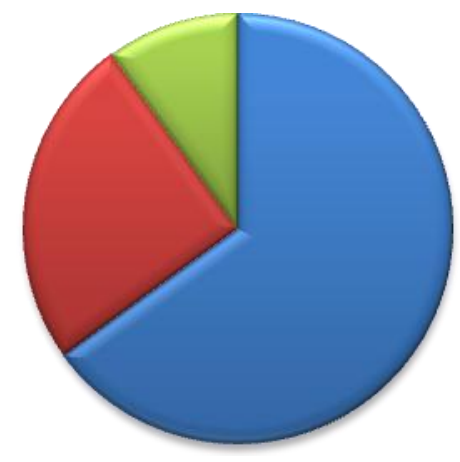

Parents $65 \%$

Friends $25 \%$

Siblings $10 \%$

Figure 3. A pie diagram showing adolescent decision making on career

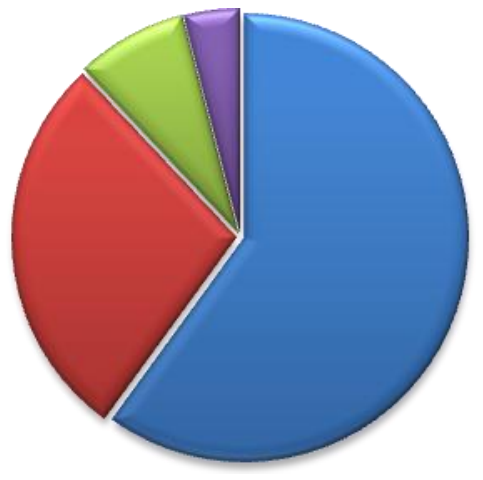

Parents $60 \%$

口 Self $28 \%$

$\triangle$ Friends $8 \%$

- Teachers $4 \%$

DISCUSSION : According to Misra A etal, School based, pretested questionnaire among 8-18 years, knowledge about protein was $14-17 \%$ \& carbohydrate was $25-27 \%$ \& fat was $18-32 \%$.In our study, knowledge about oils and fats was $43.8 \%$ and protein $67.8 \%{ }^{14}$ which is better.

According to Kapil U etal, knowledge that obesity is caused by excess intake of calories than required was known among $90.78 \%$ of adolescent school girls and 55.93\% had incorrect knowledge about diet during pregnancy. In our study knowledge about diet during pregnancy was $49 \%{ }^{15}$ which was equally comparable.

A cross sectional study by Sabya Sachi Ray etal, in school girls between 10-19 years showed, only $18 \%$ had good knowledge about puberty, puberty related problems and their prevention. $19.6 \%$ did not have any idea about mode of transmission of HIV/AIDS. In our study, 
awareness about early marriage and pregnancy was 92\%. Knowledge about HIV transmission and usage of condoms to prevent transmission was $88.3 \%$. About $11.7 \%$ were not aware of the same ${ }^{16}$.comparatively in our study subjects has better knowledge about puberty and related problems

According to Le Master PL etal, $50 \%$ of American Indian adolescents reported to use cigarette smoking ${ }^{17}$.

According to Dechenla Tsering etal study conducted in West Bengal, India, level of knowledge about harmfulness of substance use among students was $84.6 \%$ in urban and 61.5 $\%$ in rural high school students. Among 416 students 52 (12.5\%) used or abused any one of the substance. Thus they concluded that in spite of being aware of harmful effects of substance use, adolescents take up this habit. In our study awareness of alcohol and smoking hazards were known among $90 \%$ of the subjects ${ }^{18}$ which is marginally better.

Reshma P Gadkari observed that, internet, pornographic movies, books and hindi movies were used as sources of information about sex by $17 \%, 18 \%, 40 \%$ and $24 \%$ of subjects respectively above the age of 15 years. In our study internet usage was up to $44.5 \%$ as a source of information about sex and pornography ${ }^{19}$.

Global suicidal rate stands at 14.5 deaths per 10,000 as per The Lancet (vol363, P 1117) with suicide being fourth leading cause of death in 15-19 years of age group ${ }^{20}$. Suicidal ideations were noted among $20.5 \%$ of our study subjects.

Usage of helmet among two wheelers was noted only among $35.5 \%$ of our study group. Knowledge about nutritional needs, puberty and related problem, hazards of substance use was better than in other studies. But knowledge about diet during pregnancy, HIV transmission was similar to other study groups. Consumption of smoking and alcohol were acceptable up to $90 \%$ of subjects. Hence the knowledge about health hazards did not have impact on the habit. Similarly very low usage of helmet among two wheelers showed the risk taking behavior. Suicidal ideation among almost one fifth for the students shows the magnitude of risk and the lack of ability to cope up with the situation ${ }^{20}$.

CONCLUSION: Study group were medical and paramedical students in their late adolescence. The knowledge regarding nutrition, development and hazards of substance use were marginally high in our study group where as in some like health and psycho social aspects, the knowledge and attitude were similar to nonmedical / paramedical students of same age group in various other comparative studies.

Promotion of healthy lifestyles and reduction in health risk behaviors helps youths make decisions to prevent disease, and help long term positive health practices. Many youths need to realize that they are vulnerable, but they also need practical knowledge and skills. There are some major health issues of adolescents like dietary behavior, drug and alcohol, sexual behavior, injuries and physical activities. Healthy lifestyles and behaviors require correct knowledge, resources, and motivation. If the provider helps channel the motives, priorities and goals of the adolescents, then health promotion will succeed.

LIMITATIONS OF THE STUDY: The number of students were 400, belonging to medical and Paramedical colleges. More number of students and students from different parts of rural and urban areas might give better statistical results.

\section{REFERENCES :}


1. Kennedy E, Goldberg J. What are American children eating? Implications for public policy. Nutr Rev 1995;53(5):111-126.

2. Bunting H, Baggett A, Grigor J.Institute of Food, Nutrition and Human Health.PMID:23419966

3. Belmaker E, J.D. Cohen. The advisability of the prudent diet in adolescence. Journal of Adolescent Health Care1985; 6:224-32.

4. Bibiloni Mdel M, Pons A, Tur JA.Research Group on Community Nutrition and Oxidative Stress, University of Balearic Islands, Palma de Mallorca, Spain ; CIBERobn (Fisiopatología de la Obesidad y la Nutrición CB12/03/30038), Instituto de Salud Carlos III, Spain. PMID:23405220

5. Silber TJ.Division of Adolescent and Young Adult Medicine, Donald Delaney Eating Disorders Clinic, Children's National Medical Center, Washington, DC, USA. PMID:23422570

6. Burris J, Rietkerk W, Woolf K. Acad Nutr Diet 2013 J Mar;113(3):416-30. doi: 10.1016/j.jand.2012.11.016. potential relationship between diet and acne, the best dietary approach is to address each acne patient individually, carefully considering the possibility of dietary counseling. PMID:234384933

7. Mbamara SU, Obiechina NJ. Department of Obstetrics and Gynecology, Nnamdi Azikiwe University Teaching Hospital, Nnewi, Anambra State, Nigeria. kensunny30@yahoo.co.uk Public health education, awareness programs and VCT centers dedicated to young people should be established.PMID:23447920

8. Guimarães AM, Bettiol H. et al, Departamento de Enfermagem, Universidade Federal de Sergipe, Aracaju, SE, Brasil. Adolescence was a risk factor for LBW only for mothers without partners. Smoking during pregnancy and lack of prenatal care were considered to be independent risk factors for LBW.PMID:23703125

9. K.J. Duffey, I. Huybrechts, etal. Eur J Clin Nutr. Author manuscript; available in PMC 2012 August 1.Published in final edited form as: Eur J Clin Nutr. 2012 February; 66(2): 244-252. Published online 2011 September 28. doi: 10.1038/ejcn.2011.166 :PMCID: PMC3392586

10. Denering LL, Spear SE. Integrated Substance Abuse Programs, Department of Psychiatry \& Biobehavioral Sciences, University of California, Los Angeles, 11075 Santa Monica Blvd., Suite 100, Los Angeles, CA 90025, USA. ldenering@mednet.ucla.edu . Routine screening and brief intervention procedures in a mental health setting may reduce problematic substance use among college students.PMID:23210380.

11. Gakidou E, Nordhagen S, Obermeyer Z. Coverage of cervical cancer screening in 57 countries: low average levels and large inequalities. PLoS Med 2008;5(June (6)):e132.

12. zur Hausen H. Human papillomaviruses in the pathogenesis of anogenital cancer. Virology 1991;184(September (1)):9-13.

13. Jemal A, Simard EP, Dorell C. J Natl Cancer Inst. 2013 Feb 6;105(3):175-201. doi: 10.1093/jnci/djs491. Epub 2013 Jan 7. Surveillance Research Program, American Cancer Society, 250 Williams St NW, Atlanta, GA 30303, USA. ajemal@cancer.org. The overall trends in declining cancer death rates continue. However, increases in incidence rates for some HPV-associated cancers and low vaccination coverage among adolescents underscore the need for additional prevention efforts for HPV-associated cancers, including efforts to increase vaccination coverage. PMID:23297039

14. Br J Nutr. 2010 Aug;104(3):427-36. doi: 10.1017/S0007114510000681. Epub 2010 Apr 7.PMID :20370939 
15. Indian Pediatr. 1991 Oct;28(10):1135-9.Knowledge amongst adolescent girls about nutritive value of foods and diet during diseases, pregnancy and lactation. Kapil U, Bhasin S, Manocha S. PMID:1797665

16. Ethiop J Health Sci. 2011 November; 21(3): 183-189. PMCID: PMC3275869.Knowledge and Information on Psychological, Physiological and Gynaecological Problems Among Adolescent Schoolgirls of Eastern India.Sabyasachi Ray, (MD), ${ }^{1}$ Tarapada Ghosh, (MD), ${ }^{2}$ Probodh Chandra Mondal, (MD), ${ }^{2}$ Subhadeep Basak, (MD), ${ }^{1}$ Md Alauddin, (MD), ${ }^{1}$ Sujata Maiti Choudhury, (PhD), ${ }^{3,4}$ and Samiran Bisai, $(\mathrm{PhD})^{5,6}$.

17. J Adolesc Health. 2002 Jun;30(6):426-32.Tobacco use among American Indian adolescents: protective and risk factors.LeMaster PL, Connell CM, Mitchell CM, Manson SM.

18. J Pharm Bioallied Sci. 2010 Apr-Jun; 2(2): 137-140. doi: 10.4103/09757406.67005.PMCID: PMC3147098.Substance use among adolescent high school students in India: A survey of knowledge, attitude, and opinion.Dechenla Tsering, Ranabir Pal, and Aparajita Dasgupta ${ }^{1}$

19. Indian J Sex Transm Dis. 2012 Jul-Dec; 33(2): 148-149. doi: 10.4103/02537184.102140.PMCID: PMC3505300. A study for sexual health awareness in adolescent population (13-18 years) attending dermatology OPD. Reshma P. Gadkari, Gaurav Somani, Chitra S. Nayak, and Atul S. Giri

20. Journal reference: The Lancet (vol 363, p 1117).Injury-related mortality among adolescents: findings from a teaching hospital's post mortem data.Sally-Ann Ohene ${ }^{1^{*}}$, Yao Tettey ${ }^{2}$ and Robert Kumoji ${ }^{2}$

\section{AUTHORS:}

1. Suguna. S.

2. Hemachandra Reddy

\section{PARTICULARS OF CONTRIBUTORS:}

1. Assistant Professor, Department of Pediatrics, Adichunchanagiri Institute of Medical Sciences, Nagamangala tk, B.G Nagar, Mandya, Karnataka.

2. Post Graduate, Department of Pediatrics, Adichunchanagiri Institute of Medical Sciences, Nagamangala tk, B.G Nagar, Mandya, Karnataka.

\section{NAME ADRRESS EMAIL ID OF THE CORRESPONDING AUTHOR:}

Dr. Suguna $S$,

34/A, 10th Cross, $4^{\text {th }}$ Main, M Block,

Kuvempunagar, Mysore - 570023.

Email-sugunasmysore@gmail.com

Date of Submission: 10/07/2013.

Date of Peer Review: 12/07/2013.

Date of Acceptance: 18/07/2013.

Date of Publishing: 20/07/2013 